\title{
O grito e o silêncio do morder: dançando entre os dentes
}

\section{The bite's yelling and silence: dancing between the teeth}

Luane Pedroso ${ }^{1}$

Maria Brígida de Miranda ${ }^{2}$ 


\section{Resumo}

Este texto é parte da construção entre: experiências pessoais e a peça de dança intitulada Mordedores que tem como idealizadoras a brasileira Marcela Levi, do Rio de Janeiro, e a argentina Lúcia Russo, radicada no Brasil. Podemos entender a mordida como uma ação cotidiana, um hábito, já que todos a realizamos de forma natural desde os primeiros meses de vida. Quando esse natural é levado à cena, como forma de dança, ganha algumas possibilidades de investigação diferente daquilo que se observa no cotidiano. A mordida que é apresentada ultrapassa a barreira do comum e chega ao que é compulsivo, não controlável. Dentro desse contexto, a coreografia se desenrola em um jogo onde a ação de morder adquire infinitude. Este artigo relaciona o vídeo dessa peça com o universo pessoal, que dá amparo para a divisão do texto em subtópicos pensados a partir de uma ordem cronológica de lembranças.

Palavras-chave: Dança; morder; performance; corpo

\section{Abstract}

The text below discusses the articulation between: personal experiences and the dance piece titled Theethers (as a possible translation for the name in portuguese, Mordedores) idealized by Marcela Levi, from Rio de Janeiro, Brazil, and the Argentinean Lucia Russo, rooted in Brazil. It is possible to conceive the bite as an ordinary act, a habit, since every human being execute this action in a natural way from early childhood. When this naturalized act is taken to the scene as a dance, it reveals a new approach beyond bite as an ordinary act. During the dance piece, this action becomes compulsive, uncontrollable. Within this context, the choreography unfolds an endlessly game of bites. This article relates the play's audiovisual material to a personal universe that gives support to divide this text into subtopics according to a chronological memory.

Keywords: Dance; to bite; performance; body 
Morder, na minha concepção e entendimento, é um verbo que sugere ação de abocanhar algo ou alguém, travar entre os dentes, segurar, arrancar pedaços. $O$ morder é um ato primitivo e animalesco que o ser humano ainda conserva e depende dele para sua sobrevivência como, por exemplo, na mastigação do alimento que nada mais é do que a sucessão de várias mordidas a fim de triturá-lo, auxiliando-nos na supressão da necessidade fisiológica da fome.

Além do sentido mais explícito citado acima, busco em minhas memórias e lembranças alguns aspectos pessoais que me motivaram a pesquisar em torno desse ato.

\section{Dentes de Leite}

Era uma criança de 5 ou 6 anos de idade, fisicamente saudável, felizmente ativa, curiosa, reservada. Foi nesse período que sofri o primeiro abuso sexual. Eu não sabia lidar naquela época com minhas frustrações, angústias e medos, o morder foi uma forma eficaz para que eu pudesse liberar toda violência guardada sobre o dia em que fui forçada a segurar com as mãos um órgão genital masculino.

Passei a morder os amigos da escola, os tios mais velhos, a mim mesma. Fui levada à terapia para que eu pudesse entender que não era aceitável morder as pessoas e que isso não era higiênico. Dentro da Instituição Escola, a mordida entre as crianças, embora muito comum, é algo que preocupa os educadores de forma geral, pois podem derivar acidentes ocasionados pelo morder. A criança que morde o outro - ação que resiste à Instituição - deve ser disciplinada para que caiba dentro dos modelos aceitáveis e condizentes ao comportamento social do indivíduo.

O impulso de morder o outro estava aparentemente controlado em mim, a ideia de higienização e assepsia cresceram e eu decidi que realmente não deveria morder as pessoas. Concentrei-me em morder os objetos escolares e desenvolvi várias formas de auto mordida. Os braços eram o principal alvo, os ombros pela proximidade da boca também não escapavam, os dedos, os lábios, as mãos, o joelho, a coxa... tudo o que era alcançável, era mordível. Eu de fato habitava meu corpo, experimentava-o, testava os limites da dor, me sentia realmente forte e acreditava que era capaz de suportar tudo.

\section{Dentição Permanente}

$\mathrm{Na}$ adolescência aos 14 anos de idade passei a sofrer pela segunda vez, e segunda pessoa, abuso sexual. A princípio o abuso era tão camuflado e sutil fisicamente que eu não percebia ou, não queria acreditar que meu corpo estava exposto a tal violência. Recorri ao que me era conhecido como defesa - a mordida- passei a morder-me mais e mais, e o arrancar pequenos pedaços da boca era uma forma de autopunição pelo que eu estava vivenciando. A mordida no canto da boca, ao mesmo tempo em que era autopunição, me proporcionava prazer pois descarregava toda a energia acumulada que precisava sair. Durante a noite meus dentes dançavam como se triturassem a ansiedade. Eu gritava através da auto mordida, eu me silenciava através da auto mordida. 
Os abusos ficaram na memória que edito e redecoro a cada vez que converso sobre eles, o que restou em mim, constituindo meu modo de expressão, foi o morder. A mordida faz parte de uma comunicação não verbal, às vezes a utilizo como válvula de escape em ambientes onde não posso gritar, por exemplo, ou ainda na manifestação de amor por alguém. Esse ato continua sendo o grito e o silêncio do meu corpo que se forçou à docilização. Proponho pensar o meu corpo, o corpo da bailarina, e a peça Mordedores, segundo os conceitos de Michel Foucault (1999) e o estudo de Maria Brígida de Miranda intitulado Playful Training: Towards Capoeira in the Physical Training of Actors (2004), em que a autora aborda os processos de treinamentos de atores desenvolvidos no século XX. Como escreve Foucault, corpo docilizado é "um corpo que pode ser submetido, que pode ser utilizado, que pode ser transformado e aperfeiçoado" (Foucault, 1999, p.163).

Durante a fase que nomeio Dentes de Leite, as trocas estavam muito presentes. A dentição estava passando por processo de mudança, as minhas percepções sobre o mundo externo também acompanhavam essas transformações. Foi durante essa fase que comecei a entender que havia um mundo externo e exterior a mim mesma, descobri nesse mundo externo a dança, o balé clássico mais especificamente. Com 2 anos eu queria dançar, e fui! Ao contrário de muitas experiências tão precoces, a minha - segundo relatos de minha mãe - não foi traumática, foi respeitado os limites de uma criança e assim pude desistir e voltar inúmeras vezes em um movimento que de uma forma ou outra sempre me atraía para dentro da sala de dança.

Já na fase Permanente, o envolvimento com a dança foi configurando-se de maneira mais rígida, sistemática e metódica. Aos poucos, tornou-se algo profissional, treinava todos os dias e estava convicta de que seria uma bailarina de dança contemporânea. Era uma forma de esquecer o que eu vivenciava e proporcionar outro olhar para o meu corpo, um olhar menos carregado de culpa e mais cheio de possibilidades. Ainda sob o olhar de uma dança virtuosa, os treinamentos da companhia onde eu trabalhava como bailarinas estagiárias baseavam-se muito no balé clássico.

Um ano após eu entrar na companhia, o método já não fazia mais sentido para mim, eu queria dançar as perguntas e o que me ofereciam eram respostas. Fui buscar então um grupo independente da cidade onde as perguntas surgiram, onde eu comecei a enxergar outras danças, outros caminhos que traço desde então.

\section{O nascimento do siso}

Em minha busca por obras artisticamente interessantes, sob meu olhar, passei a procurar via internet performances que trouxessem alguma inquietação minha, que fossem brasileiras, contemporâneas, que estivessem em movimento.

Deparei-me com alguns vídeos da peça intitulada Mordedores ${ }^{3}$, da Improvável Produções, cuja concepção é de Marcela Levi e Lucía Russo. Encontrei na página da coreógrafa Marcela Levi ${ }^{4}$ um pouco mais sobre a peça e como se desenrolava o jogo proposto em cena. Um dos pontos de partida da obra foi justamente o ato de morder,

\footnotetext{
${ }^{3}$ Trabalho da Improvável Produções, no ano de 2015. <http://marcelalevi.com/brasil/mordedores/> Acessado em julho/2016.

${ }^{4}$ Página virtual da coreógrafa Marcela Levi <http://marcelalevi.com/> Acesso em: jun. 2016
} 
dois fatos importantes da minha vida juntaram-se, pois: a dança e a mordida. Segundo Marcela, em entrevista disponibilizada na internet ${ }^{5}$, a ação morder como base da peça, foi encontrada a partir do ruído que a mordida do jogador uruguaio Suárez deixou na Copa do Mundo de 2014. Durante um jogo entre Uruguai e Itália, Luis Suáres morde seu adversário Chiellini. Morder o adversário não é uma conduta esportiva aceitável, dentro das regras do futebol, por exemplo, é visto como potencialmente violento e agressivo. Outro exemplo esportivo a ser lembrado foi a mordida em que Mike Tyson submeteu Evander Holyfield ${ }^{6}$, arrancando-lhe um pedaço da orelha em uma luta de boxe ocorrida no ano de 1997.

Nas regras, da maioria das modalidades esportivas, o morder não é aceito pois, coloca em risco a integridade do outro. Mesmo em esportes que possuem movimentos violentos como socos e chutes - MMA por exemplo - a mordida é uma conduta antidesportiva; trata-se de um ato não asséptico que pode até mesmo provocar infecções caso haja dilaceração da carne; primitivo no qual os animais se utilizam para matar e devorar sua presa. A mordida, entre os representantes da mesma espécie, remete à ideia de canibalismo, ato condenável pelos seres sociais contemporâneos, urbanos e docilizados.

Treinar o corpo para a performance esportiva, docilizar o corpo para a performance social. A resistência do corpo à essas regras muitas vezes se faz presente e expressa, mas o corpo é adaptável, mesmo estando indóceis - internamente - nos adaptamos e nos docilizamos - externamente- para conviver em sociedade.

Retomando o pensamento de Foucault sobre corpos dóceis:

[...] o soldado tornou-se algo que se fabrica; de massa informe, de um corpo inapto, fez-se a máquina de que se precisa; corrigiram-se aos poucos as posturas; lentamente uma coação calculada percorre cada parte do corpo, se assenhoreia dele, dobra o conjunto, torna-o perpetuamente disponível. E se prolonga, em silêncio, no automatismo dos hábitos; em resumo, foi 'expulso o camponês' e lhe foi dada a 'fisionomia de soldado' (1999, p.162).

Foucault aborda a ideia de que as práticas disciplinares não são isoladas ao ambiente militar, outras instituições como escolas, fábricas e hospitais também utilizam das tecnologias para vigilância dos indivíduos que ali estão. Trazendo o conceito de tais práticas para o teatro, Miranda (2004), aponta que o século XX foi um período de muitas mudanças tanto no espaço teatral quanto no modo em que o ator era visto. Houve uma aproximação do público e isso exigiu dos atores treinamentos para essa nova vigilância e "aumento de visibilidade" do ator. (Miranda, 2004, p.80).

A partir das contribuições de Foucault (1999) e Miranda (2004) entendo que os corpos são passíveis de transformação, utilização e sujeição. Quanto mais útil tornase um corpo, mais dócil este será e, por consequência, mais disciplinado; o aumento de um desses fatores reverbera na potencialização dos outros e vice-versa.

O que observo, enquanto professora de dança, é que disciplina é uma palavra muito recorrente e disseminada ainda hoje. Durante minha experiência, como professora de balé em duas academias de dança, situadas na cidade de Florianópolis,

\footnotetext{
${ }^{5}$ Entrevista de Marcela Levi e Lucia Russo <https://www.youtube.com/watch?v=t8_GIRfwaEs> Acesso em: jun. 2016

${ }^{6}$ Link sobre a mordida proferida em Evander Holyfield <http://www1.folha.uol.com.br/fol/retro97/retro97_esporte4.htm>Acesso em: agos. 2016
} 
pude constatar que muitos adultos buscavam a dança na tentativa de enquadrar seus corpos, corrigir imperfeições, deixá-los dentro do padrão estético vigente. Por outro lado, as crianças, em sua grande maioria meninas, eram colocadas para fazer balé com a intenção de aprenderem a conviver em grupo e, sobretudo, adquirirem disciplina.

Quando a peça Mordedores traz para cena um gesto que, a priori, não concentra beleza alguma, abre-se um outro olhar para a dança, o que ela representa, quais as sensações físicas que nos acometem quando assistimos bailarinos realizando este tipo de ação, e, qual a importância de levar ao público um gesto sujo e provocador.

O corpo é parte constituinte da sociedade, atravessado por ela, marcado, que carrega inevitavelmente para cena suas cicatrizes. André Lepecki em seu texto, Coreopolítica e Coreopolícia (2011), aborda a ideia de que dança é arte e política, ao mesmo tempo, não cabendo dicotomia, ou metáforas ${ }^{7}$, se faz dança, se faz política. Nesse texto Lepecki relata algumas performances urbanas que desviaram o curso natural cotidiano da cidade, romperam com sua coreografia de fluxo constante e previsível - arte e política.

Embora Lepecki aborde de maneira macro, ou seja, a dança da cidade coreografada, sobretudo pelas forças mais impositivas e tangenciais como a polícia, os carros e a arquitetura e a dança na cidade como as performances que romperam com esse fluxo coreográfico imposto, trago tal conceito de que, dança é arte e política, para o micro, onde o rompimento com os fluxos subjetivos e individuais é possível. Entendendo o corpo como algo perecível, humano, que cheira, sente, transpira, baba, vomita e, com intuito de não espetacularizar a dança, consigo aproximar-me da simbiose que ocorre entre artEPolítica.

Frederico Morais, na década de 1970, escreve sobre o corpo político que está inserido e refletindo os embates e contradições da sociedade. Para Reis, em um texto que o autor relembra o conceito abordado por Morais, o corpo é:

Tornado palco da vida social, pois era aquele que fazia resistência política nas passeatas, no embate físico com a repressão, nas fugas, no exílio ou na guerrilha, o corpo também era o da experimentação, vivência e percepção sensíveis. E ambos uniam-se pelo fato artístico (Morais apud Reis, 2007, p.6).

O corpo, articulado e dialogando com o mundo em que vive, presenciando as contradições que estão colocadas e estabelecidas dentro de uma sociedade de consumo, afetado, está em cena. Não é o corpo alheio, alienado, fisicamente incrível. É o corpo que expõe o que sente o bicho, o animal que somos; essa exposição, embora plasticamente não agradável em um primeiro momento, adquire consistência poética pela potência que a hostilidade humana e animalesca proporciona.

Levar à cena gestos cotidianos possibilita ao espectador outro olhar para aquilo que lhe é habitual. Quando a ação morder é levada para uma apresentação de dança redefinimos, a partir daquele momento, as inúmeras formas às quais enxergamos tal gesto. Um gesto comum a todos, mas que é carregado de subjetividades e talvez o incômodo que ele gere esteja justamente no compartilhamento dessa intimidade.

${ }^{7}$ Lepecki remete-se à Randy Martin, teórico que em seu livro Critical Moves (1998) aborda as temáticas dança e política. 
Mordedores expõem e ampliam o que nos é instintivo e natural, é como se colocássemos uma lente de aumento sobre um gesto comum que é o morder, aumentando, portanto, sua frequência, intensidade, força e impulso. Silvia Geraldi (2012), retomando o conceito de Febvre sobre teatralidade da dança reflete que:

O empréstimo de uma gestualidade cotidiana pode tanto resultar num recurso para colocar em relevo uma intimidade ou memória própria do intérprete (dado que o gesto é em si portador de uma história e de uma carga simbólica que lhe são inerentes), quanto numa possibilidade de quebrar com o virtuosismo da dança (Geraldi, 2012, p.22).

Esse movimento de transpor para o público uma ação que nos é privada traz a possibilidade de diálogo comum, a possibilidade da bailarina estar mais diluída ao cotidiano, mais distante do espetáculo. De acordo com o texto de Christine Greinner (2005), o sujeito segundo Foucault está em constante processo de produção, sujeito não está acabado ou pronto. É justamente dentro dessa ideia que enxergo a peça Mordedores, e é esse o modo que encaminho minha investigação do sujeito em movimento.

A peça Mordedores inicia-se com os sete performers - sendo três mulheres e quatro homens - sentados juntos ao público, disposto em cadeiras ajustadas na forma de retângulo como se formassem um ringue. Como menciona Christine Greinner, a escolha do local, sua configuração e adequação do público, também é parte integrante e ativa da coreografia que se pretende apresentar, o ambiente para a autora tornou-se "contextual" (Greinner, 2005, p.130). No caso da peça Mordedores, de acordo com suas idealizadoras, a ideia é de que o público seja abraçado.

Trazer a dança para um espaço cênico configurado diferentemente ao do palco italiano, mais comumente utilizado, é também fazer essa relação com outro olhar para o público. A aproximação dos bailarinos, a possiblidade de interação direta, simultânea, faz com que a escolha do ringue como palco seja também parte primordial no decorrer da apresentação. O público, nesse espaço concentrado e não disperso, está em cena o tempo todo, não há proteção, ele está exposto, com o rosto em evidência, assim como os bailarinos, o espectador ali sentado não é anônimo, permanece misturado e também se faz potencialmente mordedor.

Os bailarinos entram e saem desse espaço retangular delimitado. Há a possibilidade de escolha entre o confronto e o afeto; essa escolha dá-se pelo modo com que se estabelecem as mordidas entre si. O tempo todo é um jogo de concessões, de ceder e entrar em confluência com o outro corpo que está ali, também vulnerável. Josette Féral em seu texto Por uma poética da performatividade: o teatro performativo cita que para Huyssen performance tem relação com a arte e com a estética. Além de Huyssen, Féral traz em seu texto a visão de Schechner sobre performance, que possui um olhar mais antropológico e intercultural. A performance nesse caso estaria presente em várias ações cotidianas não necessariamente artísticas, o autor traz o conceito de perfomance como experiência e competência. (Féral, 2008, p.199).

Na peça Mordedores, a ação performática parte de um gesto não necessariamente artístico, e direciona o envolvimento do público a partir da experiência que todos temos em comum: o morder. 
O mastigar é o primeiro ato da mordida que ocorre na peça. Os performers, ainda sentados ao lado do público, começam a mastigar alguns pedaços de plástico bolha. A posição dos bailarinos se difere da posição da plateia, eles encontram-se em estado de prontidão, denunciando dessa forma que algo irá acontecer. Nesse primeiro momento não há contato visual direto com o público, cria-se uma espécie de linha ou campo estabelecidos apenas entre os 7 performers/bailarinos que estão sentados. Três bailarinos mastigam o plástico bolha por aproximadamente oito minutos, após isso, dois outros se levantam e começam a morderem-se um ao outro, passando bem próximo ao público, realizando a volta em torno do ringue estabelecido. Quando os bailarinos mordedores passam por aquele que estava mastigando o plástico bolha, este também entra no jogo do morder como se fosse capturado. Dessa forma estabelece-se o principal ato da peça, o morder e ser mordido.

Durante a apresentação, há diferentes tipos de mordidas que acontecem, no entanto, a que prevalece por mais tempo é a mordida agressiva, como se quisessem devorar uns aos outros, sem utilizar os braços ou as mãos, prendem-se por meio do abocanhar. Em um determinado momento uma das bailarinas caminha de quatro, lembrando o andar de alguns animais, pelo lado de fora do público, emitindo sons. Esta é a primeira ruptura que percebo. Até este momento a peça seguia um fluxo de ações que me levaram a um estado de linearidade, de caminho a ser percorrido, sem curvas ou desvios. Quando a bailarina desloca-se do centro e modifica o olhar do público, esse fluxo é quebrado promovendo novos acontecimentos a partir daí.

Enquanto a bailarina caminha, outro que permanece sentado emite alguns sons ritmando-os com aqueles emitidos pela caminhante. Os outros quatro também sentados em uma só cadeira mordem-se, agora de forma mais lenta, calma, com certo grau de erotismo, sendo levados e conduzidos pelos sons emitidos. Para Gomez Peña, em seu texto En defensa del arte del performance, o autor afirma que:

A performance também é um lugar interno, inventado por cada um de nós de acordo com nossas próprias aspirações políticas e necessidades espirituais mais profundas, nossos desejos e obsessões sexuais mais obscuras, nossas lembranças mais perturbadoras e nossa busca inexorável de liberdade" (Peña, 2005, p.204) ${ }^{8}$.

A bailarina retorna ao ringue, são sempre os mesmos sons, ritmados, cadenciados, que são interrompidos pelo desejo de morder. A segunda ruptura acontece: uma linha tênue entre o erótico e o animal, o querer manter-se e o querer devorar-se; apesar da mordida no ato de devorar não ser de fato entre os dentes, a sensação é de canibalismo.

Ocorre uma não saciedade, uma não finitude, pois a vontade de morder, de devorar sempre retornará. Há um descanso no morder quando os bailarinos passam a assoprarem-se levando a boca até a pele do outro emitindo barulhos; os barulhos geram diferentes gargalhadas, tudo regado em uma grande euforia, aí está a terceira ruptura. Sentados em uma cadeira, dois bailarinos mordem uma bailarina, de maneira

${ }^{8}$ El performance también es un lugar interno, inventado por cada uno de nosotros, de acuerdo con nuestras propias aspiraciones políticas y necesidades espirituales más profundas; nuestros deseos y obsesiones sexuales más oscuras; nuestros recuerdos más perturbadores y nuestra búsqueda inexorable de libertad. (Tradução Luane Pedroso). 
lenta e retomando a ideia de erotização. A bailarina permanece alheia a esse acontecimento, como se tivesse retomado a consciência e ao mesmo tempo em estado catatônico, uma música ao fundo em conjunto com a baixa no estado de euforia. Dois bailarinos levantam-se, dançam e saem...

$\mathrm{Na}$ peça há um entrelaçamento entre o que é do homem animal e o que é do homem humano. É nesse entrelaçar que reside a meu ver, a simbiose entre artEPolítica e, consequentemente, a potência artística geradora de questionamentos em relação ao cotidiano, aos hábitos socialmente construídos, ao que somos realmente, ao que a dança pode trazer para o público. Em um limiar que transita entre o erótico e o violento, o jogo que ocorre com os corpos que se mordem parece ser uma concentração da energia acumulada. Ali, no ringue, estabelecido pelo posicionamento das cadeiras da plateia, os bailarinos passam a tomar consistência que antecede a do homo sapiens e remete muito mais a figura de animais, que mordem, choram, emitem sons, mastigam. A assepsia e docilização tão fortemente presentes na sociedade contemporânea são deixadas de lado para abrir espaço às possiblidades desse corpo do homem animal.

\section{Considerações dos 32}

Seguindo a ordem cronológica estabelecida no início do texto, agora com os 32 dentes devidamente nascidos, proponho-me a mastigar algumas percepções que ainda não estão prontas para serem digeridas. Assim, as considerações a seguir não são conclusões, mas parte de um processo digestivo que se iniciou na boca.

Assisti ao vídeo da peça algumas vezes no conforto da minha sala, sem o risco de ser eventualmente mordida. O distanciamento e o número de vezes que sentei em frente à televisão, me proporcionaram uma experiência de observadora mais analítica e menos sensibilizada pela presença física. Acredito que presenciar ao vivo me traria muitas outras sensações, outras análises e inquietações que eu ainda não pude vivenciar.

Na rede social de Marcela Levi, há fotos do trabalho cujas legendas são as falas das pessoas que assistiram a peça. Algumas delas afirmam que sentiram nojo, outras que acharam engraçado, uma perguntou se eles já haviam pensado nas pessoas que sofreram violência e estavam assistindo. Em poucas palavras, já recolho perguntas que também me fiz ao assistir o vídeo, tais perguntas são importantes para que o abocanhar da pesquisa continue a acontecer.

Para finalizar este texto deixo a citação de Helena Katz: "a coreografia torna-se a estruturação de uma forma de refletir sobre e de dar forma à sociedade moderna, 0 que faz da dança um índice indispensável para as pesquisas em cultura" (Katz, 2009).

Sigamos...

\section{Referências}

FÉRAL, Josette. Por uma poética da performatividade: o teatro performativo. Sala Preta. v.8, p. 197-210. 2008.

FOUCAULT, Michel.Vigiar e punir:nascimento da prisão. 20. ed. Petrópolis: Vozes, 
1999. 348 p. Tradução de Raquel Ramalhete.

GERALDI, Sílvia. O lugar da teatralidade na dança contemporânea. Sala Preta, vol. 12, n. 2, p. 13-26, dez 2012.

GREINNER, Christine. O corpo - pistas para estudos indisciplinares. São Paulo: Annablume, 2005, 152p.

LEPECKI, André. Coreopilítca e coreopolícia. Revista Ilha, Florianópolis, v. 13, n.1, p.41 - 60, jan./jun. 2011-2012.

MIRANDA, Maria Brígida de. Playful Training: Towards Capoeira in the Physical Training of Actors. Austrália, 2004.Tese (Doutorado) - La Trobe University, LTU.

PEÑA, Guillermo Goméz. En defensa del arte del performance. Horizontes Antropológicos, Porto Alegre, ano 11, n. 24, p. 199-226, jul./dez. 2005

REIS, Pulo Roberto de Oliveira. O corpo político na arte brasileira - anos 60 e 70 . In: CONGRESO INTERNACIONAL DE CIENCIAS, ARTES Y HUMANIDADES EL CUERPO DESCIFRADO, Memorias del III Congreso Internacional de Ciencias, Artes y Humanidades "El Cuerpo Descifrado". México: Universidad Autónoma Metropolitana, Unidad Azcapotzalco, 2007. p. 798 - 804. Disponível em: <http://congreso.cuerpodescifrado.com/p/memorias-de-congresos-anteriores.html>. Acesso em: 10 jul. 2016.

Recebido em: 06/09/2016

Aprovado em: 16/11/2016 